\title{
DIGITALCOMMONS
}

@WAYNESTATE -

Wayne State University

$1-1-2013$

\section{Re-Arrest Among Juvenile Justice-Involved Youth: An Examination Of The Static And Dynamic Risk Factors}

Jun Sung Hong

Wayne State University, fl4584@wayne.edu

Joseph P. Ryan

University of Michigan

Yu-Ling Chiu

University of Illinois at Urbana-Champaign

Bushra Sabri

Johns Hopkins University

\section{Recommended Citation}

Hong, J.S., Ryan, J.P., Chiu, Y.L., \& Sabri, B. (2013). Re-arrest among juvenile justice-involved youth: An examination of the static and dynamic risk factors. Residential Treatment for Children and Youth, 30(2), 131-148.

Available at: http://digitalcommons.wayne.edu/soc_work_pubs/32 
NOTICE IN COMPLIANCE WITH PUBLISHER POLICY: This is the author's final accepted manuscript version, post-peer-review, of an article published by the Taylor \& Francis Group in Residential Treatment for Children and Youth on May 13, 2013, available online at http://dx.doi.org/10.1080/0886571X.2013.785230 


\title{
Re-Arrest Among Juvenile Justice-Involved Youth: An Examination Of The Static And Dynamic Risk Factors
}

\author{
JUN SUNG HONG ${ }^{\mathrm{a}}$, JOSEPH P. RYAN ${ }^{\mathrm{b}}, \mathrm{YU}^{-L I N G ~ C H I U}{ }^{\mathrm{c}}$, BUSHRA SABRI $^{\mathrm{d}}$ \\ a School of Social Work, Wayne State University, Detroit, MI 48202 (Corresponding Author, f14584@wayne.edu) \\ b School of Social Work, University of Michigan \\ c School of Social Work, University of Illinois at Urbana-Champaign \\ d School of Nursing, Johns Hopkins University
}

\begin{abstract}
The purpose of this study is to investigate the static and dynamic risk factors for re-arrest among detained youth by examining gender, race/ethnicity, age, special education and mental health variables (i.e., anger/irritability, depression/anxiety, somatic complaints, suicide ideation, thought disturbances, and traumatic experiences). The demographic profiles of detained youth with one admit were also compared with those with multiple admits to the juvenile detention center. With regards to static risk factors, older, white, and special education were significantly at risk of re-arrest. Concerning dynamic risk factors, only anger/irritability predicted re-arrest. Practice implications are also discussed.
\end{abstract}

Keywords delinquency; juvenile justice; mental health; re-arrest; special education

\section{INTRODUCTION}

Over two million American youth were arrested for delinquent acts in 2007 (Puzzanchera, 2009), an increase from 2002 in which 1.6 million were arrested. Property offense accounted for $39 \%$ of arrests, followed by public order offense $(25 \%)$, interpersonal offense (24\%), and drug law violation (12\%; Snyder \& Sickmund, 2006). Youth who are arrested are at a heightened risk of school truancy and dropout (Zabel \& Nigro, 1999), substance use (Tripodi \& Springer, 2007), and incarceration as adults (Synder et al., 2003). These youth are also likely to relapse into the juvenile justice system. The large number of youth re-entering the juvenile justice system has heightened research interest in understanding the risk factors associated with re-arrest. Some propose that incarceration may deter juvenile offenders from committing crimes by making the consequences of illegal activities tangible (Lin, 2007). Others argue that incarceration holds little promise to prevent future crime, and in some cases, incarceration offenders may actually increase their likelihood of re-offending (Lin, 2007). Further, detention centers are perceived as a "training ground for criminals," where offenders become more deeply entrenched in criminal activities, develop delinquent identities, associate with negative peers, and learn more sophisticated criminal techniques (Lin, 2007). Regrettably, there is no national data on juvenile re-arrest rate because many state jurisdictions are hesitant to report the re-arrest rates in an effort to demonstrate the effectiveness of their juvenile justice system (Snyder \& Sickmund, 2006).
The definition of re-arrest also varies from state to state and across research studies (Myner et al., 1998). In Illinois, for example, juvenile re-arrest refers to youth reentering the Illinois Center facilities within three years upon release (Illinois Department of Juvenile Justice, year). According to the Illinois Department of Corrections, rearrest rate for youth after three years of exiting a correctional facility was $46.6 \%$ in 2001 . However, this rate reflects under-reporting of the actual re-arrest rate of youth in that it only counts those who returned to a correctional facility within three years of release. The actual number of youth who returned to the criminal justice system is unknown (Coalition for Juvenile Justice, 2009). Likewise, much is unknown about the types of youth in juvenile detention center who are particularly likely to be re-arrested. Additional research is needed to investigate the predictors of re-arrest among juvenile delinquents. The purpose of this study is to identify static and dynamic risk factors for re-arrests among juvenile justice-involved youth.

\section{THEORETICAL FRAMEWORK}

A number of theories offer explanations for possible causes of juveniles re-offending. Criminal propensity theory focuses on a combination of internal (e.g., mental health status) and external (e.g., family, school, community) factors that may place youth at risk of re-arrest. According to the criminal propensity theory, certain mental traits (such as low self-control, impulsivity, inability to delay gratification, the inability to learn from punishment) make juveniles more prone to criminal behaviors and subsequent arrests or re-arrests. Furthermore, the institutional context of the 
school and community provide activating and inhibiting experiences for criminal propensity to manifest through criminal behaviors (Burfeind \& Bartusch, 2011; Gottfredson \& Hirschi, 1990; Henry et al., 1996; Watt, Howells, \& Delfabbro, 2004; Wilson \& Herrnstein, 1985) and subsequent re-arrests. In contrast, social control theory places importance on mechanisms of social control that contribute to desistance from crime. Social control mechanisms such as quality of relationship with family members, academic achievement, and involvement in structured recreational facilities have been found to predict re-arrest among juvenile offenders (Watt et al., 2004).

Risk factors for juvenile crimes and re-arrests are also classified into two types: static and dynamic (Andrews \& Bonta, 1998; Salgado, 2007). Static risk factors refer to characteristics that cannot be changed or intervened upon such as age, gender, race/ethnicity, and special education. Dynamic risk factors refer to characteristics that can be changed through interventions such as substance use and mental health status. The static factors in the present study consist of age, gender, race/ethnicity, and special education, and dynamic risk factors include substance-use and mental health problems. These two types of risk factors are further described below.

\section{Static Risk Factors}

Studies have reported that juvenile re-arrest is associated with several socio-demographic factors such as gender, race/ethnicity, age, and special education. Researchers have consistently found that males are considerably more likely than females to engage in conflicts and violent acts (see Espelage, Mebane, \& Swearer, 2004) and are more likely to be re-arrested (Dembo et al., 1998; Hoge, Andrews, \& Leschied, 1996). Rodriguez's (2007) study, which investigated the effects of restorative justice program in decreasing the likelihood of re-arrest, found that girls were most successful in participating in such programs and were also less likely to be re-arrested than boys. However, more recent findings on gender differences in delinquency and re-arrest have been inconsistent and some researchers have argued that the gap between criminal activities of boys and girls has narrowed (Garbarino, 2005), which reflects a major change in societal responses to girls criminal activities and violent behaviors (Goodkind et al., 2009; Steffensmeier et al., 2005; Zahn et al., 2008). Relatively few researchers have examined female juveniles exclusively who are at risk of re-arrest (Mullis et al., 2004). Tille and Rose (2007) found that behavioral problems, exposure to an unstable lifestyle, and family environment were correlated with re-arrest among females.

Race/ethnicity is another static risk factor that has been commonly explored in a number of studies on juvenile re-arrest. Researchers have reported that African American youth have much higher rates of arrest and rearrest than Whites and other races/ethnicities (Pope \& Snyder, 2003; Sickmund, 2004; Stahl, 2003). A more re- cent research conducted by Mbuba (2005) however refutes these findings. Using two data sets obtained from the Office of Youth Development in the Department of Public Safety and Corrections in Louisiana, Mbuba (2005) found no statistical relationship between race/ethnicity and the likelihood of re-arrest among juvenile offenders. His finding debunks the myth of a 'typical offender' being an African American or a racial/ethnic minority. An earlier study by Mbuba (2004) also reports that the methods most frequently used to predict juvenile re-arrest have been derived from stereotypical conceptions (e.g., racial/ethnic minority youth are more likely to recidivate than do white youth) with little or no scientific verification. The author argues that a more substantive and quantitative-oriented procedure is necessary to enhance the effectiveness of predictions for juvenile re-arrest. Moreover, predicting re-arrest varies according to race/ethnicity when other factors, such as family environment are controlled for (Baffour, 2006; Rivaux et al., 2006; Schwalbe et al., 2006; Wierson \& Forehand, 1995). To illustrate, Rivaux et al.'s (2006) findings indicate that family problems were significantly associated with re-arrest for Hispanic youth whereas psychological problems predicted re-arrest for African American youth.

In addition to gender and race/ethnicity, age has been frequently examined in several studies on juvenile delinquency and re-arrest (Benda, Corwyn, \& Toombs, 2001; Zara \& Farrington, 2009). Study findings have suggested that delinquency and criminal activities at younger age were significant predictors for re-arrest. For instance, Benda et al. (2001) found that delinquency at early age of onset (11.7 years of age) predicted subsequent offending and rearrest during adolescence. Trulson et al. (2005) also reported that younger children at first contact with the juvenile justice system were significantly more likely to be rearrested than older youth. Minor et al.'s (1997) two-year follow-up study, which consisted of a group of 475 youth referred to a juvenile court for the first time, also found that younger juveniles were significantly more likely to be re-arrested than older youth. Myers (2003) examined the likelihood, seriousness, and timing of re-arrest for 494 violent youth offenders in Pennsylvania. Consistent with previous studies, Myers' (2003) findings also indicated that younger youth were more likely than older youth to be rearrested.

A large number of youth involved in the juvenile justice system have special educational needs because of learning disabilities, mental illness, and substance use (Maschi et al., 2008; Quinn et al., 2005). According to Quinn et al. (2005), the most common disabilities for juveniles in corrections were emotional disturbance $(47.7 \%)$, learning disabilities (38.6\%), and mental retardation $(9.7 \%)$. Furthermore, evidences suggest an association between low academic achievement, learning disabilities, mental health status, and juvenile re-arrests (Cottle, Lee, \& Heilbrun, 2001; Katsiyannis \& Archwamety, 1997; Vacca, 2008; Zhang et al., 2011). A meta-analysis conducted by 
Cottle, Lee, and Heilbrun (2001) report that the predictors for juvenile re-arrest include prior experiences in special education and low school attendance, along with low test scores and low IQ scores. It is important to identify youth in the juvenile justice system with disabilities because offenders with disabilities are more prone to recidivism and re-arrests than those without disabilities (Rutherford et al., 2002; Shelley-Tremblay, O'Brien, \& LanghinrichsenRohling, 2007; Zhang et al., 2011). However, the prevalence rates of juvenile delinquent youth in special education have varied widely (30\% to $50 \%$, Rutherford et al., 2002).

\section{Dynamic Risk Factors}

Juvenile offenders are also more likely than youth in the general population to have substance-use and mental health problems (Braithwaite et al., 2003; Lopez-Williams et al., 2006; Maschi et al., 2008), and juvenile offenders with substance-use problems are more likely than other offenders to be re-arrested (Eden, Campbell, \& Weir, 2006; Marczyk et al., 2003; Stoolmiller \& Blechman, 2005; Sullivan et al., 2007). Stoolmiller and Blechman (2005) found that substance-abusing youth were likely to be re-arrested regardless of the prior reports of delinquency, gender, race/ethnicity, age, follow-up time, or data source. Likewise, several researchers have also reported that the rate of youth in the juvenile justice system who are diagnosed with serious mental disorder is double the estimated rate in the general youth population. For instance, Teplin et al.'s (2002) study in Cook County, Illinois found that $60 \%$ of males and $68 \%$ of females in the juvenile correctional system had diagnosis-specific functional impairment for one or more psychiatric disorders. Rosenblatt, Rosenblatt, and Biggs (2000) also reported that $31 \%$ of youth arrested had prior experiences with the public mental health system, and $20 \%$ of the youth receiving services were arrested. Youth receiving mental health services in King County, Washington, were significantly more likely to be referred to the juvenile justice system than those not receiving mental health services (Vander Stoep, Evens, \& Taub, 1997).

These findings indicate that substance-use and mental health problems are dynamic risk factors that can lead to arrest and re-arrest. However, much is unknown about the likelihood of re-arrest when considering substance-use and mental health indicators of Massachusetts Youth Screening Instrument (MAYSI-2). Building on studies that utilized MAYSI (Espelage et al., 2003; Marczyk et al., 2003; Tille $\&$ Rose, 2007), we focus on the relationship between substance-use and MAYSI-2-identified mental health risk factors and re-arrest. This study builds on research on juvenile justice by identifying static and dynamic risk factors for re-arrest and targets for prevention efforts. More specifically, we investigate whether static risk factors such as gender, race/ethnicity, age, and special education, and dynamic risk factors including substance-use and MAYSI-2 mental health problems are associated with re-arrest from a sample of juvenile justice-involved youth in Illinois. We first compare the static and dynamic risk factors of youth who were arrested for the first time with youth who were returned to the detention center multiple times. Practice implications are also discussed.

\section{METHODS}

\section{Sampling Procedures}

Sample for this study consists of 756 youth detained in a juvenile detention center in Illinois from 2004 to 2009 period. Of the total sample, $369(48.8 \%)$ were detained at the center once and $387(51.2 \%)$ re-entered multiple times, from 2004 to 2008. All of these youth were adjudicated for violence, weapons, property destruction, substance-use, or 'other' offenses, prior to eighteen years of age. In collaboration with a juvenile detention center, data were collected. Youth detained in the center agreed to participate in the study, and the University Institutional Review Board and the center approved the study procedure. Youth were informed that their participation was strictly voluntary and that they could withdraw from the study at any time.

\section{Measures}

For this study, the Detention Intake Screening Instrument, which included scores on the presenting offense, prior contacts, prior criminal convictions, risk of failure to appear, legal status, aggravating factors, and mitigating factors, was used as an assessment tool for evaluating the severity of the offense. With regards to the dependent variable, readmission was gathered from administrative records and was dichotomized $(1=$ yes; $0=$ no). The independent variables include static risk factor variables (i.e., gender, race/ethnicity, age, special education) and dynamic risk factor variables (i.e., alcohol/drug, anger/irritability, depression/anxiety, somatic complaints, suicidal ideation, thought disturbances, and traumatic experiences). Gender was coded as $1=$ female, $0=$ male; male was the reference variable. Race/ethnicity was dichotomized as $1=$ nonAfrican American (i.e., whites, Hispanics, Asians, American Indians, others), 0 = African American; white was the reference variable. Age refers to the age of the youth on December 31, 2004. Special education and MAYSI-2 variables were dichotomized as $1=$ yes and $0=$ no. The reference group for special education variable was 'not receiving special education'; the reference variable for MAYSI-2 was traumatic experiences. MAYSI-2 has reportedly been a reliable and valid screening tool for identifying youth who may need an immediate response to mental health problems (Grisso et al., 2001).

\section{Analyses}

We conducted the analyses by computing descriptive statistics for the variables and estimating a Cox Regression model using SPSS 16.0. We used survival analysis to in- 
vestigate the influence of variables on survival rates. This analysis considers the different impact between groups on the timing of this event (Land, McCall, \& Parker, 1994). Cox Regression assesses the effects of each independent variable, which contributes to the log odds of re-arrest while adjusting for the effects of other independent variables (see Allison, 1999). In the present study, youth entered and exited the juvenile detention center at different points in times, and the age of these youth varied. For example, a youth may have been re-arrested after his or her eighteenth birthday, in which the case would not be processed in the juvenile justice system. The time variables in consideration for the survival analysis are times between the first and second arrest, between the first arrest and end date observation (December 31, 2008), and between first arrest and eighteenth birthday. Survival models adjust for these variations by censoring observations. Observations are censored if the target event (re-arrest) does not occur prior to the end of data collection. The coefficients are interpreted similarly to those from logistic regression.

\section{RESULTS}

\section{Descriptive Statistics}

The number and percentage of the number of admits and types of offense at first and last admissions to the detention center are displayed in Table 1. Youth were arrested 2.45 times on average while those with multiple admit were rearrested 3.84 times. For the types of offenses first committed, the majority of the youth $(46.3 \%)$ were charged with violent act (46.3\%), followed by 'other' acts (29.4\%), property offense $(19.7 \%)$, substance-use (2.8\%), and weapons charge $(1.8 \%)$. For youth who were arrested only once, $51.9 \%$ were charged violent act, followed by other acts $(27.6 \%)$, property offense $(15.9 \%)$, substance-use $(2.4 \%)$, and weapon $(2.2 \%)$. For those with multiple admits, $41.0 \%$ were arrested for violent act, followed by $31.2 \%$ for 'other acts,' $23.2 \%$ for property offense, $3.1 \%$ for substance-use, and $1.5 \%$ for weapons. Regarding the types of offenses committed at last (most recent) entry, $40.8 \%$ of all youth were incarcerated for violent act, $35.4 \%$ for other act, $19.7 \%$ for property offense, $2.8 \%$ for substance-use, and $1.5 \%$ for weapons charge. For youth arrested multiple times, $41.8 \%$ were detained for 'other act,' $30.2 \%$ for violent act, $24.2 \%$ for property offense, $3.1 \%$ for substanceuse, and $0.8 \%$ for weapons.

Static risk factors are also included in Table 1 . The total sample consists of $26.3 \%$ females and $73.7 \%$ males. Among youth with one admit, $70.7 \%$ were male and $29.3 \%$ were female. For juveniles with multiple admits, males accounted for $76.5 \%$. African Americans comprise $71.7 \%$ of all youth, followed by $25.1 \%$ whites. Due to low sample size, youth of 'other races/ethnicities' were eliminated from this study. Among youth with one admit, $65.0 \%$ were African Americans and $31.7 \%$ were whites. For youth admitted multiple times, $78.0 \%$ were African Americans while $18.9 \%$ were whites. Age refers to the age of the youth on December 31,2004. The average age at entry was 12.34 years old. For youth with one admit, the average age was 12.27 and those with multiple admit was 12.40 . Among all youth, $28.5 \%$ reported having received special education. For youth with only one admit, $16.2 \%$ received special education, while $40.2 \%$ of youth admitted multiple times received special education.

Table 1. Types of Offense, and Static and Dynamic Risk Factors $(\mathrm{N}=756)$

\begin{tabular}{|c|c|c|c|}
\hline & $\begin{array}{c}\text { All Youth } \\
756(100.0 \%)\end{array}$ & $\begin{array}{l}\text { One Admit } \\
369(48.8 \%)\end{array}$ & $\begin{array}{c}\text { Multiple Admits } \\
387(51.2 \%)\end{array}$ \\
\hline \multicolumn{4}{|l|}{ Number of admits } \\
\hline Mean(SD) & $2.45(2.03)$ & - & $3.84(2.03)$ \\
\hline \multicolumn{4}{|l|}{ Types of offense at first admit } \\
\hline Violence & $351(46.3 \%)$ & $192(51.9 \%)$ & $159(41.0 \%)$ \\
\hline Weapon & $14(1.8 \%)$ & $8(2.2 \%)$ & $6(1.5 \%)$ \\
\hline Property & $149(19.7 \%)$ & $59(15.9 \%)$ & $90(23.2 \%)$ \\
\hline Substance-use & $21(2.8 \%)$ & $9(2.4 \%)$ & $12(3.1 \%)$ \\
\hline Other & $223(29.4 \%)$ & $102(27.6 \%)$ & $121(31.2 \%)$ \\
\hline \multicolumn{4}{|l|}{ Types of offense at last admit } \\
\hline Violence & $309(40.8 \%)$ & - & $117(30.2 \%)$ \\
\hline Weapon & $11(1.5 \%)$ & - & $3(0.8 \%)$ \\
\hline Property & $149(19.7 \%)$ & - & $94(24.2 \%)$ \\
\hline Substance-use & $21(2.8 \%)$ & - & $12(3.1 \%)$ \\
\hline Other & $268(35.4 \%)$ & - & $162(41.8 \%)$ \\
\hline \multicolumn{4}{|l|}{ Static risk factors } \\
\hline \multicolumn{4}{|l|}{ Gender } \\
\hline Female & $199(26.3 \%)$ & $108(29.3 \%)$ & $91(23.5 \%)$ \\
\hline Male & $557(73.7 \%)$ & $261(70.7 \%)$ & $296(76.5 \%)$ \\
\hline \multicolumn{4}{|l|}{ Race/ethnicity } \\
\hline African American & $542(71.7 \%)$ & $240(65.0 \%)$ & $302(78.0 \%)$ \\
\hline White & $190(25.1 \%)$ & $117(31.7 \%)$ & $73(18.9 \%)$ \\
\hline \multicolumn{4}{|l|}{ Age } \\
\hline Mean(SD) & $12.34(2.1)$ & $12.27(2.32)$ & $12.40(1.90)$ \\
\hline Special education & $216(28.5 \%)$ & $60(27.8 \%)$ & $156(72.2 \%)$ \\
\hline \multicolumn{4}{|l|}{ Dynamic risk factors } \\
\hline \multicolumn{4}{|l|}{ MAYSI-2 } \\
\hline Alcohol/drugs & $64(8.4 \%)$ & $11(17.2 \%)$ & $53(82.8 \%)$ \\
\hline Anger/irritability & $158(20.8 \%)$ & $44(27.8 \%)$ & $114(72.2 \%)$ \\
\hline Depression/anxiety & $109(14.4 \%)$ & $28(25.7 \%)$ & $81(74.3 \%)$ \\
\hline Somatic complaints & $181(23.9 \%)$ & $62(34.3 \%)$ & $119(65.7 \%)$ \\
\hline Suicidal ideation & $61(8.0 \%)$ & $18(29.5 \%)$ & $43(70.5 \%)$ \\
\hline Thought disturbance & $79(10.4 \%)$ & $21(26.6 \%)$ & $58(73.4 \%)$ \\
\hline Traumatic experiences & $277(36.5 \%)$ & $97(35.0 \%)$ & $180(65.0 \%)$ \\
\hline
\end{tabular}

Dynamic risk factor variables are also presented in Table 1. Slightly over eight percent $(8.4 \%)$ of all youth reported using alcohol/drugs while only $3.0 \%$ for youth with one admit, and $13.7 \%$ for those with multiple admits used alcohol or drugs. Concerning whether the youth were angry or irritable, which consisted of $20.8 \%$ of all youth, $11.9 \%$ of youth with one admit, and $29.4 \%$ of youth with multiple admits reported 'yes'. We also found that among $14.4 \%$ all youth, $7.6 \%$ of youth with one admit, and $20.9 \%$ with multiple admits reported being depressed or anxious. For somatic complaints, $23.9 \%$ of total youth indicated 'yes' while $16.8 \%$ of those with one admit and $30.7 \%$ with multiple admits did. For suicidal ideation, which included $8.0 \%$ of all youth, $4.9 \%$ of youth with one admit, and $11.1 \%$ of youth with multiple admits responded 'yes'. Thought disturbances were reported by $10.4 \%$ of all youth; $5.7 \%$ for those with one admit, and $14.9 \%$ for multiple admits. And finally, $36.5 \%$ of all youth had prior traumatic 
experiences; $26.2 \%$ of youth with one admit and $46.4 \%$ with multiple admits indicated having traumatic experiences.

\section{Regression Analyses}

Results of the Cox Regression analysis of re-arrest are displayed in Table 2. Results indicate that race/ethnicity and age were significant predictors. That is, African American youth were less likely (OR: .64; $\mathrm{p}<.01)$ than white youth, and older youth were 1.19 times more likely $(\mathrm{p}<.01)$ than younger youth to be re-arrested. Contrary to past findings, we found that gender was not a significant predictor in this study. However, youth who reported receiving special education were 2.11 times more likely to be re-arrested ( $p$ $<.01)$ compared to those without special educational needs. In contrast to previous studies, the majority of the MAYSI2 variables did not significantly predict re-arrest, and only one variable was statistically significant when compared with the reference variable. That is, youth who reported being angry or irritable were 1.64 times more likely ( $p$ $<.01)$ to be re-arrested, compared to youth with traumatic experiences.

Table 2. Cox Regression for the Likelihood of Re-Arrest $(N=756)$

\begin{tabular}{lccc}
\hline Variable & $B(\mathrm{SE})$ & $\operatorname{Exp}(B)$ & $p$ \\
\hline Static risk factors & & & \\
$\quad$ Female (Male) & $-.15(.13)$ & 0.86 & 0.24 \\
African American (White) & $-.44(.13)$ & 0.64 & $.00^{\star *}$ \\
Age at 2004 & $.17(.03)$ & 1.19 & $.00^{\star *}$ \\
Special education & $.74(.12)$ & 2.11 & $.00^{\star *}$ \\
Dynamic risk factors & & & \\
MAYSI-2 (Traumatic experience) & & & \\
Alcohol/drugs & $.33(.19)$ & 1.39 & $.08 \dagger$ \\
Anger/irritability & $.49(.18)$ & 1.64 & $.01^{\text {** }}$ \\
Depression/anxiety & $.24(.18)$ & 1.27 & 0.17 \\
Somatic complaints & $.20(.15)$ & 1.23 & 0.17 \\
Suicidal ideation & $-.24(.21)$ & 0.79 & 0.29 \\
Thought disturbance & $.27(.19)$ & 1.31 & 0.15 \\
\hline
\end{tabular}

$\mathrm{tp}<.10 ;{ }^{*} \mathrm{p}<.05 ;{ }^{* *} \mathrm{p}<.01 ;$ Note: Reference variables are denoted in parenthesis.

\section{DISCUSSION}

The present study examined the static and dynamic risk factors for juvenile re-arrest. Our results were contrary to several studies (Pope \& Snyder, 2003; Stahl, 2003), which found that African American youth are more likely to be admitted to the juvenile detention center more than once compared to youth of other racial/ethnic groups. We found that African American youth are less likely than white youth to be re-arrested. Age was also another predictor for re-arrest. Contrary to previous studies (Myers, 2003; Trulson et al., 2005), our results indicate that older youth were more likely to be re-arrested than younger youth who are involved in the juvenile justice system. Older youth are more likely to have the opportunity to engage deviant behavior and delinquent acts than younger youth (Watson, 2007). Moreover, as the Court-Ordered Residential Programs and Services suggests, older youth in the juvenile justice system are more likely than younger youth to be resistant to rehabilitation (Tyler, Darville, \& Stalnaker, 2001).

With regards to gender, our results suggest that there is no gender difference in juvenile re-arrest (see Sondheimer, 2001). Unlike past studies, which found that males were more likely to recidivate than females (Dembo et al., 1998; Hoge, Andrews, \& Leschied, 1996), gender was not statistically significant in our study. Perhaps this is because there have been increases in female youth arrests and adjudications for crimes over the past 25 years (Goodkind et al., 2009; Snyder \& Sigmund, 2006; Steffensmeier et al., 2005). It may also be that we only examined a small segment of the juvenile justice population such as those who enter a juvenile detention center, which mostly consists of males. Interestingly, recent studies have also shown that while female youth arrests for simple assault increased by $24 \%$ from 1996 to 2006, male youth arrests decreased by $4 \%$, according to the FBI Uniform Crime Report data. However, our understanding of female re-arrest is still limited due to lack of research on female juvenile re-arrest, and it is important for researchers to pay particular attention to re-arrest among female youth.

With regards to the association between special education and juvenile re-arrest, our results are consistent with previous study findings (Cottle, Lee, \& Heilbrun, 2001; Katsiyannis \& Archwamety, 1997). Youth in juvenile detention center with special educational needs are significantly more likely to recidivate than those without special educational needs. This is also consistent with national findings that youth in special education are overrepresented in the juvenile justice system. According to the National Center on Education, Disability and Juvenile Justice, more than one in three youth in juvenile correctional facilities have previously received special educational services. Forty-five percent of youth in the justice system are reportedly diagnosed with a learning disability. Although there are few studies that investigate the overrepresentation of special needs youth in the justice system, low academic performance, along with lack of access to special educational services in the detention center may contribute to delinquency and re-arrest (Ohio Coalition for the Education of Children with Disabilities, 2006). Further research on special education and juvenile justice involvement is critical because proper identification can help assure that these youth receive tailored services based on their needs.

Of the MAYSI-2 variables, we found only one variable that predict re-arrest among the youth in the detention center. Youth identified as 'angry or irritable' are likely to be re-arrested, which was consistent with findings from previous studies (Espelage et al., 2003; Tille \& Rose, 2007). Tille and Rose (2007) posited that re-arrested youth may feel angry at being in the juvenile justice system repeatedly, thus likely to engage in risky behaviors and delinquency.

This study also has some limitations, many of which are based on the variables available in the dataset. African American youth were overrepresented while youth of other 
race/ethnic groups were underrepresented in the sample, which made it difficult to ascertain the likelihood of rearrest for youth other than African Americans and whites. Moreover, relying on youth reports rather than gathering data from multiple sources of information (e.g., school reports) may have introduced unmeasured biases. Although youth reports are important data source for understanding the predictors for multiple admits to the juvenile detention center, they do not necessarily reflect objective measures of re-arrest. And finally, several potentially relevant predictors of juvenile re-arrest (e.g., home and neighborhood environments) were not included in this study. These limitations aside, this study adds to the knowledge on juvenile re-arrest, which has practice implications.

\section{Practice Implications}

Effective intervention strategies for juvenile offenders are imperative considering that juvenile offenders without treatment are likely to be resistant to change, and antisocial and criminal behaviors often continue into adulthood (Tarolla et al., 2002). Earlier studies consistently reported that recidivism and re-arrest for youth who received no treatment ranged from $60 \%$ to $80 \%$ (Farrington, 1995; Jenson \& Howard, 1998;Lattimore, Visher, \& Linster, 1995). In order to develop and implement effective programs and strategies for reducing the likelihood of re-arrest, our findings highlight the importance of conducting a thorough assessment of youth involved in the justice system, which must include multiple factors at various contexts. Although this might be a daunting task, best practices require an assessment of the social ecology (Swearer \& Espelage, 2004) to accurately determine the effects of programs and strategies for incarcerated and re-arrested youth.

Although special education is associated with delinquency involvement and re-arrest, evidence suggests that many juvenile correctional facilities do not comply with the Individuals with Disabilities Education Act (IDEA; Mears \& Kelly, 1999; National Council on Disability, 2003). IDEA stipulates that youth involved in the juvenile justice system are entitled to receive the same services as students in public school, namely, "free and appropriate education in the least restrictive environment" (ShelleyTremblay et al., 2007, p. 380). Nevertheless, practitioners need to work closely with school administrators to ensure that educational needs of youth with special needs are met. Improving the quality of educational services for juvenile justice-involved youth is the first step. School improvement program such as the Ohio Community Collaboration Model (OCC) is a good example, which includes strategic connections with family and community resources and has been found to be effective in improving academic performance and in reducing behavioral problems that might lead to re-arrest (Ohio Coalition for the Education of Children with Disabilities, 2006). In addition, youth with anger or irritability problem are an increased risk of re-arrest. Thus, programs that assist youth in managing negative emotions are suggested. One such program is the Lochman's Anger Coping Program, which assists aggressive and disruptive youth to understand the physiology of aggression and anger, and reinforces proper coping strategies such as selftalk. Lochman's (1992) study found that youth who participated in the program were more likely to control their anger, increase self-esteem and learn proper social problemsolving skills. Other programs, which have been proven efficacy in reducing anger and increasing social competence, are the Interpersonal Cognitive Problem-Solving, Kazdin's Social Competence Training Program, the Brainpower Program, and the Positive Adolescents Choice Training Program (Wilson, 2000).

A number of residential treatment programs, from therapeutic interventions to punitive correctional systems, have been established nationwide to treat juvenile offenders whose severity of offense or number of prior convictions warrants incarceration (Abram, 2006). Residential treatment programs normally house juvenile offenders with psychiatric or substance-use problems who have been proven to be incompatible with non-secure environments (e.g., foster care) but do not merit commitment to a psychiatric hospital or correctional facilities. These programs provide a combination of substance-se and mental health treatment programs in a highly structured environment (OJJDP, n.d.). Regrettably, prior evaluation research has consistently suggested that these programs are largely ineffective, as evidenced by high rates of re-offense and rearrest (e.g., Greenwood, 1996; Jenson \& Howard, 1998). More recent research demonstrates mixed results. To illustrate, Bettmann and Jasperson's (2009) review of adolescent residential treatment programs, reports that therapeutic settings are effective for some of the clients. However, the researchers also note that there is a major dearth of research that assesses the effectiveness of the program elements and there is little agreement on what constitutes treatment success. Nevertheless, residential treatment centers should assess the multidimensional factors for juvenile crimes and re-offense, and incorporate multi-systemic and cognitive-behavioral approaches. Family, multisystemic, and cognitive-behavioral interventions hold the greatest promise for reducing behavioral problems among juvenile justice-involved youth (see Tarolla et al., 2002, for a review).

That said, families, schools, and communities also all have a hand in preventing juvenile delinquency and rearrest. Effective interventions require practitioners to collaborate with family, schools, and communities to provide needed assistance for youth who are involved in the justice system, which can subsequently improve their psychosocial well-being and decrease the likelihood of re-offense and re-arrest.

\section{REFERENCES}


1. Abrams, L. S. (2006). Listening to juvenile offenders: Can residential treatment prevent recidivism? Child and Adolescent Social Work Journal, 23, 61-85.

2. Allison, P. D. (1999). Logistic regression using the SAS system: Theory and application. Cary, NC: SAS Institute.

3. Andrews, D. A. \& Bonta, J. (1998) The Psychology of Criminal Conduct (2nd ed.). Cincinnati, OH: Anderson.

4. Archwamety, T., \& Katsiyannis, A. (1998). Factors related to recidivism among delinquent females at a state correctional facility. Journal of Child and Family Studies, 7, 59-67.

5. Bacon, S., Paternoster, R., \& Brame, R. (2009). Understanding the relationship between onset age and subsequent offending during adolescence. Journal of Youth and Adolescence, 38, 301-311.

6. Baffour, T. D. (2006). Ethnic and gender differences in offending patterns: Examining family group conferencing interventions among at-risk adolescents. Child and Adolescent Social Work Journal, 23, 557-578.

7. Bailey, G. W. (1989). Current perspectives on substance abuse in youth. Journal of the American Academy of Child and Adolescent Psychiatry, 28, 151-162.

8. Benda, B. B., Corwyn, R. F., \& Toombs, N. J. (2001). Recidivism among adolescent serious offenders: Prediction of entry into the correctional system for adults. Criminal Justice and Behavior, 28, 588613 .

9. Bettmann, J. E., \& Jasperson, R. A. (2009). Adolescents in residential and inpatient treatment: A review of the outcome literature. Child \& Youth Care Forum, 38, 161-183.

10. Braithwaite, R. L., Conerly, R. C., Robillard, A. G., Stephens, T. T., \& Woodring, T. (2003).

11. Alcohol and other drug use among adolescent detainees. Journal of Substance Use, 8, 126-131.

12. Burfeind, J. W., \& Bartusch, D.J. (2011). Juvenile delinquency: An integrated approach (2nd edition). Sudbury, MA: Jones and Bartlett Learning.

13. Carney, M. M., \& Buttell, F. (2003). Reducing juvenile recidivism: Evaluating the wraparound services model. Research on Social Work Practice, 13, 551-568.

14. Coalition for Juvenile Justice (2009). Illinois JJDPA formula grant application attachment 1: Program narrative. Retrieved October 17, 2009, from http://juvjustice.njjn.org/media/resources/resource_281.pdf

15. Cottle, C. C., Lee, R. J., \& Heilbrun, K. (2001). The prediction of criminal recidivism in juveniles: A meta-analysis. Criminal Justice and Behavior, 28, 367-394.

16. Dembo, R., Schmeidler, J., Nini-Gough, B., Sue, C. C., Borden, P., \& Manning, D. (1998). Predictors of recidivism to a juvenile assessment center: A three year study. Journal of Child and Adolescent Substance Abuse, 7, 57-77.

17. Edens, J. F., Campbell, J. S., \& Weir, J. M. (2006). Youth psychopathy and criminal recidivism: A meta-analysis of the psychopathy checklist measures. Law and Human Behavior, 31, 53-75.

18. Espelage, D. L., Cauffman, E., Broidy, L., Piquero, A. R., Mazerolle P., \& Steiner, H. (2003). A cluster-analytic investigation of MMPI profiles of serious male and female juvenile offenders. Journal of American Academy of Child \& Adolescent Psychiatry, 42, 770-777.

19. Espelage, D. L., Mebane, S. E., \& Swearer, S. M. (2004). Gender differences in bullying: Moving beyond mean level differences. In D. L. Espelage \& S. M. Swearer (Eds.) Bullying in American schools: A social-ecological perspective on prevention and intervention. (pp.15-35). Mahwah, NJ: Lawrence Erlbaum Associates.

20. Farrington, D. P. (1995). The development of offending and antisocial behavior from childhood: Key findings from the Cambridge Study in Delinquent Development. Journal of Psychology and Psychiatry in Allied Disciplines, 36, 929-964.

21. Garbarino, J. (2005). See Jane hit: Why girls are growing more violent and what we can do about it. New York: The Penguin Press.

22. Goodkind, S., Wallace, J. M., Shook, J. J., Bachman, J., \& O’Malley, P. (2009). Are girls really becoming more delinquent? Testing the gender convergence hypothesis by race and ethnicity, 1976-2005. Children and Youth Services Review, 31, 885-895.

23. Gottfredson, M., \& Hirschi, T. (1990). A general theory of crime. Stanford, CA: Stanford University Press
24. Greenwood, P. (1996). Responding to juvenile crime: Lessons learned. Future of Children, 6, 75-85.

25. Grisso, T., Barnum, R., Fletcher, K. E., Cauffman, E., \& Peuschold, D. (2001). Massachusetts youth screening instrument for mental health needs of juvenile justice youth. Journal of the American Academy of Child and Adolescent Psychiatry, 40, 541-548.

26. Henry, B., Caspi, A., Moffit, T.E., \& Silva, P.A. (1996). Temperamental and familial predictors of violent and nonviolent criminal convictions: From age 3 to age 18. Developmental Psychology, 32, 614-623.

27. Hoge, R. D., Andrews, D. A., \& Leschied, A. W. (1996). An investigation of risk and protective factors in a sample of youthful offenders. Journal of Child Psychology and Psychiatry, 37, 419-424.

28. Illinois Criminal Justice Information Authority (2008). Trends and issues 2008, a profile of criminal and juvenile justice in Illinois: 1995-2005. Retrieved October 11, 2009, from http://www.icjia.state.il.us/public/pdf/TI\%202008/T\&I\%202008\%2 0Full\%20Report.pdf

29. Jensen, J. M., \& Howard, M. O. (1998). Youth crime, public policy, and practice in the juvenile justice system: Recent trends and needed reforms. Social Work, 43, 324-334.

30. Katsiyannis, A., \& Archwamety, T. (1997). Factors related to recidivism among delinquent youth in a state correctional facility. Journal of Child and Family Studies, 6, 43-55.

31. Katsiyannis, A., Ryan, J. B., Zhang, D., \& Spann, A. (2008). Juvenile delinquency and recidivism: the impact of academic chievement. Reading \& Writing Quarterly, 24, 177-196.

32. Krysik, J., \& LeCroy, C. W. (2002). The empirical validation of an instrument to predict risk of recidivism among juvenile offenders. Research on Social Work Practice, 12, 71-81.

33. Land, K., McCall, P., \& Parker, K. (1994). Logistic versus hazards regression analyses in evaluation research: An exposition and application to the North Carolina Court Counselor's Intensive Protective Supervision Projects. Evaluation Review, 18, 411-437.

34. Lattimore, P. K., Visher, C. A., \& Linster, R. L. (1995). Predicting rearrest for violence among serious youthful offenders. Journal of Research in Crime and Delinquency, 32, 54-83.

35. Lin, J. (2007). Exploring the impact of institutional placement on the recidivism of delinquent youth. Unpublished doctoral dissertation, New York University, New York, NY. National Institute of Justice, Washington, DC.

36. Lipsey, M. W., \& Wilson, D. B. (1998). Effective intervention for serious juvenile offenders: A synthesis of research. In R. Loeber \& D. P. Farrington (Eds.), Serious and violent juvenile offenders. Thousand Oaks, CA: Sage.

37. Lochman, J. E. (1992). Cognitive-behavioral intervention with aggressive boys: Three-year follow-up and preventive effects. Journal of Consulting and Clinical Psychology, 60, 426-432.

38. Lopez-Williams, A., Stoep, A. V., Kuo, E., \& Stewart, D. G. (2006) Predictors of mental health service enrollments among juvenile offenders. Youth Violence and Juvenile Justice, 4, 266-280.

39. Marczyk, G. R., Heilbrun, K., Lander, T., \& DeMatteo, D. (2003). Predicting juvenile recidivism with the PCL: YV, MAYSI, and YLS/CMI. International Journal of Forensic Mental Health, 2, 7-18.

40. MacKinnon-Lewis, C., Kaufman, M. C., \& Frabutt, J. M. (2002). Juvenile justice and mental health: Youth and families in the middle. Aggression and Violent Behavior, 7, 353-363.

41. Maschi, T., Hatcher, S. S., Schwalbe, C. S., \& Rosato, N. S. (2008) Mapping the social service pathways of youth to and through the juvenile justice system: A comprehensive review. Children and Youth Services Review, 30, 1376-1385.

42. Mbuba, J. M. (2004). Juvenile recidivism: An analysis of race and other socio-demographic predictors within three intervention modalities in the state of Louisiana. Unpublished doctoral dissertation, Louisiana State University, Baton Rouge: LA.

43. Mbuba, J. M. (2005). A refutation of racial differentials in the juvenile recidivism rate hypothesis. African Journal of Criminology and Justice Studies, 1, 51-68.

44. Mears, D. P., \& Kelly, W. R. (1999). Assessment and intake processes in juvenile justice processing: Emerging policy considerations. Crime and Delinquency, 45, 508-529. 
45. Minor, K. I., Hartmann, D. J., \& Terry, S. (1997). Predictors of juvenile court actions and recidivism. Crime and Delinquency, 43, 328-344.

46. Mullis, R. L., Cornille, T. A., Mullis, A. K., \& Huber, J. (2004). Female juvenile offending: A review of characteristics and contexts. Journal of Child and Family Studies, 13, 205-218.

47. Myers, D. L. (2003). The recidivism of violent youth in juvenile and adult court: A consideration of selection bias. Youth Violence and Juvenile Justice, 1, 79-101.

48. Myner, J., Santman, J., Cappelletty, G. G., \& Perlmutter, B. F. (1998). Variables related to recidivism among juvenile offenders. International Journal of Offender Therapy and Comparative Criminology, 42, 65-80.

49. National Council on Disability (2003). Addressing the needs of youth with disabilities in the juvenile justice system: The current status of evidence-based research. Washington, DC: National Council of Disability. Retrieved December 25, 2012, from http://www.ncd.gov.newsroom/publications/juvenile.html

50. Neighbors, B., Kempton, T., \& Forehand, R. (1992). Co-occurrence of substance abuse with conduct, anxiety, and depression disorders in juvenile delinquents. Addictive Behaviors, 17, 379-386.

51. Office of Juvenile Justice and Delinquency Prevention (n.d.). Residential treatment centers. Retrieved December 25, 2012, from http://www.ojjdp.gov/mpg/progTypesResidentialTreatment.aspx

52. Ohio Coalition for the Education of Children with Disabilities (2006). Special education and juvenile justice: An overview and analysis of prevention and intervention policy and program developments. Retrieved November 14, 2009, from http://www.ocecd.org/ocecd/h_docs/061220_JJSpEdRept.pdf

53. Pope, C. E., \& Snyder, H. N. (2003). Race as a factor in juvenile arrests. Office of Juvenile Justice and Delinquency Prevention. Washington, DC: U.S. Department of Justice.

54. Pullmann, M. D., Kerbs, J., Koroloff, N., Veach-White, E., Gaylor, R., \& Sieler, D. (2006). Juvenile offenders with mental health needs: Reducing recidivism using wraparound. Crime and Delinquency, 52, 375-397.

55. Puzzanchera, C. (2009). Juvenile arrests 2007. U.S. Department of Justice. Retrieved October 11, 2009, from http://www.ncjrs.gov/pdffiles1/ojjdp/225344.pdf

56. Quinn, M., Rutherford, R., Leone, P., Osher, D., \& Poirer, J. (2005). Youth with disabilities in juvenile corrections: A national survey. Exceptional Children, 71, 339-345.

57. Redding, R. E. (2008, August). Juvenile transfer laws: An effective deterrent to delinquency? Office of Juvenile Justice and Delinquency Program. Washington, DC: U.S. Department of Justice.

58. Risler, E. A., Sutphen, R., \& Shields, J. (2000). Preliminary validation of the juvenile first offender risk assessment index. Research on Social Work Practice, 10, 111-126.

59. Rivaux, S. L., Springer, D. W., Bohman, T., Wagner, E. F., \& Gil, A G. (2006). Differences among substance abusing Latino, Anglo, and African-American juvenile offenders in predictors of recidivism and treatment outcome. Journal of Social Work Practice in the Addictions, 6, 5-29.

60. Rodriguez, N. (2007). Restorative justice at work: Examining the impact of restorative justice resolutions on juvenile recidivism. Crime and Delinquency, 53, 355-379.

61. Rosenblatt, J. A., Rosenblatt, A., \& Biggs, E. E. (2000). Criminal behavior and emotional disorder: Comparing youth served by the mental health and juvenile justice systems. Journal of Behavioral Health Services Research, 27, 227-237.

62. Rutherford, Jr., R. B., Bullis, M., Anderson, C., \& Griller-Clark, H. M. (2002). Youth with disabilities in the correctional system: Prevalence rates and identification issues. College Park, MD: Center for Collaboration and Practice, American Institutes for Research.

63. Schwalbe, C. S., Fraser, M. W., Day, S. H., \& Cooley, V. (2006). Classifying juvenile offenders according to risk of recidivism: Predictive validity, race/ethnicity, and gender. Criminal Justice and Behavior, 33, 305-324.

64. Shelley-Tremblay, J., O'Brien, N., \& Langhinrichsen-Rohling, J. (2007). Reading disability in adjudicated youth: Prevalence rates, current models, traditional and innovative treatments. Aggression and Violent Behavior, 12, 376-392.
65. Sickmund, M. (2004). Juveniles in corrections. OJJDP Bulletin. Washington, DC: Office of Juvenile Justice and Delinquency Prevention.

66. Snyder, H., Espiritu, R., Huizinga, D., Loeber, R., \& Petechuk, D. (2003). Prevalence anddevelopment of child delinquency. Child Delinquency Bulletin Series: Office of JuvenileJustice and Delinquency Prevention.

67. Snyder, H. N., \& Sickmund, M. (2006). Juvenile offenders and victims: 2006 National Report. Office of Juvenile Justice and Delinquency Prevention. Washington, DC: Department of Justice.

68. Sondheimer, D. L. (2001). Young female offenders: Increasingly visible yet poorly understood. Gender Issues, 19, 79-90.

69. Stahl, A. L. (2003). Delinquency cases in juvenile courts. Office of Juvenile Justice and Delinquency Prevention. Washington, DC: U.S. Department of Justice.

70. Steffensmeier, D., Schwartz, J., Zhong, H., \& Ackerman, J. (2005). An assessment of recent trends in girls' violence using diverse longitudinal sources: Is the gender gap closing? Criminology, 43, 355405.

71. Stoolmiller, M., \& Blechman, E. A. (2005). Substance use is a robust predictor of adolescent recidivism. Criminal Justice and Behavior, 32, 302-328.

72. Sullivan, C. J., Veysey, B. M., Hamilton, Z. K., \& Grillo, M. (2007). Reducing out-of-community placement and recidivism: Diversion of delinquent youth with mental health and substance use problems from the justice system. International Journal of Offender Therapy and Comparative Criminology, 51, 555-577.

73. Swearer, S. M., \& Espelage, D. L. (2004). Introduction: A socialecological framework of bullying among youth. In D. L. Espelage \& S. M. Swearer (Eds.), Bullying in American schools: A socialecological perspective on prevention and intervention (pp. 1-12). Mahwah, NJ: Lawrence Erlbaum Associates, Publishers.

74. Tarolla, S. M., Wagner, E. F., Rabinowitz, J., \& Tubman, J. G. (2002). Understanding and treating juvenile offenders: A review of current knowledge and future directions. Aggression and Violent Behavior, 7, 125-143.

75. Teplin, L. A., Abram, K. M., McClelland, G. M., Dulcan, M. K., \& Mericle, A. A. (2002). Psychiatric disorders in youth in juvenile detention. Archives of General Psychiatry, 59, 1133-1143.

76. Tille, J. E., \& Rose, J. C. (2007). Emotional and behavioral problems of 13-to-18-year-old incarcerated female first-time offenders and recidivists. Youth Violence and Juvenile Justice, 5, 426-435.

77. Tinklenberg, J. A., Steiner, H., Huckaby, W. J., \& Tinklenberg, J. R. (1996). Criminal recidivism predicted from narratives of violent juvenile delinquents. Child Psychiatry and Human Development, 27, 69-79.

78. Tripodi, S. J., \& Springer, D. W. (2007). Treatment of substanceabusing juvenile delinquents. In A. R. Roberts \& D. W. Springer (Eds.), Forensic Social Work in Juvenile and Criminal Justice (3rd ed.). Springfield, IL: Charles C. Thomas.

79. Trulson, C. R., Marquart, J. W., Mullings, J. L., \& Caeti, T. J. (2005). In between adolescence and adulthood: Recidivism outcomes of a cohort of state delinquents. Youth Violence and Juvenile Justice, 3, 355-387.

80. Tyler, J., Darville, R., \& Stalnaker, K. (2001). Juvenile boot camps: A descriptive analysis of program diversity and effectiveness. The Social Science Journal, 38, 445-460.

81. U.S. Department of Justice (2009). Delinquency cases in juvenile court. Retrieved October 16, 2009, from http://www.ncjrs.gov/pdffiles1/ojjdp/224538.pdf

82. Vacca, J. S. (2008). Crime can be prevented if schools teach juvenile offenders to read. Children and Youth Services Review, 30, 1055-1062.

83. Wasserman, G. A., Miller, L. S., \& Cothern, L. (2000, May). Prevention of serious and violent juvenile offending. Office of Juvenile Justice and Delinquency Prevention. Retrieved May 9, 2010, from http://www.ncjrs.gov/pdffiles1/ojjdp/178898.pdf

84. Watson, C. M. (2007). Examining juvenile crime and recidivism. Unpublished master's thesis, Marshall University, Huntington.

85. Watt, B., Howells, K., \& Delfabbro, P. (2004). Juvenile recidivism: criminal propensity, social control and social learning theories. Psychiatry, Psychology and Law, 11, 141-153. 
86. Wierson, M., \& Forehand, R. (1995). Predicting recidivism in juvenile delinquents: The role of mental health diagnoses and the qualification of conclusions by race. Behaviour Research and Therapy, 33, 63-67.

87. Wilson, D. B., Gallagher, C. A., \& MacKenzie, D. L. (2000). A meta-analysis of corrections-based education, vocation, and work programs for adult offenders. Journal of Research in Crime and Delinquency, 37, 347-368.

88. Wilson, J. J., Rojas, N., Haapanen, R., Duxbury, E., \& Steiner, H. (2001). Substance abuse and criminal recidivism: A prospective study of adolescents. Child Psychiatry and Human Development, 31 , 297-312.

89. Wilson, J. Q., \& Hernstein, R. J. (1985). Crime and human nature. New York: Simon \& Schuster.

90. Windle, M. (1990). A longitudinal study of antisocial behaviors in early adolescence as predictors of late adolescent substance use: Gender and ethnic group differences. Journal of Abnormal Psychology, 99, 86-91.

91. Zabel, R. H., \& Nigro, E. A. (1999). Juvenile offenders with behavioral disorders, learning disabilities, and no disabilities: Self-reports of personal, family, and school characteristics. Behavioral Disorders, $25,22-40$.

92. Zahn, M., Brumbaugh, S., Steffensmeier, D., Feld, B., Morash, M., Chesney-Lind,...Kruttschnitt, C. (2008). Violence by teenage girls: Trends and context. U.S. Department of Justice. Retrieved November 13, 2009, from http://www .ojp.usdoj.gov.

93. Zara, G., \& Farrington, D. P. (2009). Childhood and adolescent predictors of late onset criminal careers. Journal of Youth and Adolescence, 38, 287-300.

94. Zhang, D., Barrett, D.E., Katsiyannis, A., \& Yoon, M. (2011). Juvenile offenders with and without disabilities: Risks and patterns of recidivism. Learning and Individual Differences, 21, 12-18. 